\title{
PARA ALÉM DO DUALISMO NATUREZA/CULTURA: FICÇÕES DO CORPO FEMININO
}

\author{
Rita Terezinha Schmidt ${ }^{*}$ \\ Para Márcia Hoppe Navarro, \\ amiga e colega de todas as horas \\ In memoriam \\ .... a resistência não tem valor em si mesma. \\ É o "conteúdo" da resistência que determina o seu mérito, a sua necessidade moral
}

(SONTAG, 2008, p. 184)

\begin{abstract}
: this text probes into the legacy of a central dualism of western culture nature $v s$. culture - to examine how the tropo of the "natural woman" constructed in the modern period bears upon the narrative logics of two representative European novels of the XIX century: Gustave Flaubert's Madame Bovary and Leon Tolstoi's Ana Karenina. Then, it focuses on some scenes of Kate Chopin's The awakening and Virgínia Woolf's To the lighthouse to show to what extent the representation of the female characters' experience of corporeality des-figure the dualisms upon which traditional cultural gender norms are predicated and, therefore, subvert the inscription of the body as the locus of the reproduction of femininity.
\end{abstract}

KEYWORDS: dualisms, fictional narratives, representations, gender, corporeality

A constância do dualismo natureza/cultura e seus efeitos na concepção do corpo feminino são indissociados de interpretações das relações mulher/natureza, as quais ocupam um lugar central na imaginação da cultura ocidental. Na mitologia, nas artes visuais, nas doutrinas religiosas, nos tratados filosóficos, nas ciências médicas e sociais, na psicanálise, na literatura e nos meios midiáticos, o corpo feminino é sacralizado pela sua capacidade gerativa, exaltado pela beleza, repudiado pela impureza, erotizado pelo olhar masculino, controlado pelo aparato estatal, e explorado e aviltado pela violência de discursos e práticas que se disseminam no campo social. Tudo o que sabemos sobre o corpo feminino, no passado e no presente, existe na forma de representações e discursos, que são efeitos de mediações, nunca inocentes e nunca isentos de interpretações. Isso quer dizer que o significado cultural do corpo feminino não se reduz à referencialidade de um ser empírico de carne e osso, mas constitui um constructo simbólico, produzido e reproduzido na cultura e na sociedade ocidental ao longo dos tempos. A partir de um breve recorte do legado filosófico sobre os dualismos natureza/cultura, mente/corpo, sujeito/objeto e suas consequências para a concepção do

\footnotetext{
* Professora da Universidade Federal do Rio Grande do Sul (UFRGS).
} 
sujeito e corpo feminino, pontuo algumas transformações históricas que produziram o tropo da "mulher natural" e examino representações da "mulher desnaturada" em dois romances expoentes do realismo do século XIX - Madame Bovary e Ana Karenina. Na sequência, me detenho em cenas específicas de The Awakening, de Kate Chopin, e de To The Lighhouse, de Virgínia Woolf, enquanto cenas de des-figuração do corpo. Procuro mostrar como a representação de experiências da corporealidade e subjetividade de personagens femininas desessencializa os tradicionais dualismos cultura/natureza, mente/corpo, colocando sob rasura as normas de gênero que, na modernidade, disciplinam a inscrição simbólica do corpo como locus de reprodução da feminidade.

\section{DUALISMOS RECORRENTES}

As categorias conceituais da natureza e da cultura constituem um dualismo fundador, muito caro à cultura humanista e o mais duradouro e persistente ao longo da história do mundo ocidental. Dos mitos clássicos à era moderna, na filosofia, na teologia, na antropologia e na literatura, para mencionar alguns campos do saber, esse dualismo operou como um modelo coerente para dar sustentação a distinções universalizantes entre concepções de humano e de não humano, e entre distinções entre seres homem e mulher. Impulsionado pelo desejo de explicar filosoficamente a natureza das coisas a partir de como elas são, Aristóteles foi um dos primeiros pensadores a explorar noções sobre a natureza do ser humano a partir da diferença sexual. Suas reflexões sobre o estatuto das mulheres na polis o levaram a deduzir a sua inferioridade como algo dado pela natureza, ou seja, a inferioridade deriva de um defeito constitutivo que é o seu corpo frio, incapaz, portanto, de transformar o sangue menstrual em sêmen, substância que carrega a latência do ser humano completo. Segundo seus argumentos, o homem doa a substância do ser (a alma, a forma) na cópula, enquanto que a mulher, embora não destituída de elementos da alma, supre o ser de forma passiva, apenas com a matéria, inferior à forma. Isso significa dizer que a latência da substância não se concretiza na concepção do ser feminino, um ser incompleto por natureza.

É importante observar que a oposição essencial entre substância e matéria está vinculada, particularmente em On the generation of animals (2007), ao campo da reprodução, e é nesse contexto que o corpo humano, declinado no feminino, sofre um rebaixamento conceitual em razão de sua inscrição na esfera de processos da natureza, suas leis e seus ciclos. Destituída de substância, a mulher é definida como um ser com alma de menos, o que vai agregar à conotação de inferioridade um juízo valorativo sobre faculdades cognitivas (no caso, a incapacidade da mulher de exercer a razão em sua plenitude, o que significa ser barrada do acesso à transcendência) ${ }^{1}$. Por isso,

\footnotetext{
${ }^{1}$ Platão é, muitas vezes, ambíguo em relação às mulheres, mas no Timeus suas posições ficam mais claras. Neste texto, Platão afirma que somente os homens têm alma por serem criados diretamente pelos deuses e que a razão é o elemento divino no homem assim como o inteligível é o elemento divino na natureza. Ao colocar em discussão o que significa viver de forma irrepreensível, diz que aqueles que vivem corretamente retornam às estrelas, mas aqueles que são covardes podem, com razão, ter sido supostamente transformados na natureza das mulheres na segunda geração. Essa "caída" progressiva pode continuar em reencarnações sucessivas até que a situação seja revertida. É evidente que somente os homens, por serem completos, podem aspirar a essa possibilidade. Para as mulheres, essa progressão é inexistente. De modo geral, quando Platão se manifesta sobre o status inferior das mulheres, é para se
} 
Aristóteles argumenta que, sendo a inteligência dos homens superior por natureza, é natural que eles sejam destinados a mandar nas mulheres, pois essas são "como uma metade dos seres livres" (ARISTÓTELES, 2004, cap. IV, pár. 17). No contexto de seu argumento, os termos que definem o que se qualifica e pode ser reconhecido como humano ficam muito claros, uma vez que, para efeitos práticos, em questões que dizem respeito à organização social e ao funcionamento do Estado, a própria definição do humano implica em construções diferenciadas e hierarquizadas. Dessa forma, as mulheres, os escravos e os bárbaros (os estrangeiros) correspondem a gradações nessa hierarquia, mas é significativo que somente o ser da mulher é concebido como uma forma inferior de vida humana pela matéria corpórea associada à animalidade, o que veio a constituir uma premissa não questionada no âmbito da cultura ocidental e, particularmente, nas disciplinas humanistas, ao longo de séculos.

Com raízes na epistemologia patriarcal sobre a diferença entre os sexos, pode-se dizer que o dualismo natureza/cultura produziu a moldura dominante do humano declinado pelo masculino em sua relação com um ser menos humano, uma categoria entre o humano e o não humano que veio a definir o ser mulher, definição decorrente da racionalização do mimetismo biológico que ratificou as representações de uma relação pretensamente "natural" do corpo das mulheres com a natureza. Com a emergência do chamado "homem da razão", um conceito-metáfora que constitui a marca registrada do campo conceitual associado à filosofia e à ciência modernas, o dualismo natureza/cultura foi reescrito e ressignificado, primeiramente no racionalismo cartesiano, cuja clássica formulação cogito ergo sum jogou o corpo para a ordem das leis mecânicas da natureza - res extensa - expulsando-o definitivamente do campo filosófico como algo que não é sujeito porque externo a ele, pertencente à natureza do sensível e, portanto, fonte de obscurecimento e confusão da razão ${ }^{2}$. O método filosófico que consagrou a racionalidade e a objetividade como baluartes do saber moderno, legitimando a cisão mente/corpo a partir da premissa da superação de suas limitações epistemológicas por uma mente incorpórea, contribuiu decisivamente para uma essencialização ontológica do homem enquanto sujeito soberano do conhecimento, uma subjetividade autônoma e racional diante desse outro, o mundo objetificado de uma natureza que, via de regra, assume o estatuto do feminino. Em um certo sentido, há uma sintonia entre a filosofia cartesiana, racional e teórica, e o empiricismo prático de Francis Bacon, um dos fundadores das ciências naturais no século XVII, no que se refere ao feminino. Bacon, em sua Nova filosofia (Novum Organum Scientiarum, 1620), define a natureza como feminina e a concebe como um modelo mecânico uniforme, acionado por forças de causa e efeito, passíveis de serem compreendidas, controladas e

referir a uma degeneração da natureza humana perfeita, uma vez que essa é divina, uma concepção que o pensamento cristão de Santo Agostinho, expresso em suas Confissões irá refutar, ao conceber o corpo como inimigo. A esse respeito, conferir Timeus (tradução para o inglês de Benjamin Jowett) no website http://www.gutenberg.org/files/1572/1572-h/1572-h.htm (acessado em 20 de fevereiro de 2012). Reflexões pontuais sobre as posições de Platão e Aristóteles com relação a temas relacionados ao feminino e às mulheres constam na coletânea Engendering Origins: Critical Feminist Readings in Plato and Aristotle, organizada por Bat-Ami Bar On (Albany: State University of New York, 1994).

2 A razão como uma ideia inata, desenvolvida no seu Discurso do Método (São Paulo: Martin Claret, 2011), recebeu forte influência do neoplatonismo vigente no Renascimento. O filósofo contemporêno Daniel Dennett (participante do evento Fronteiras do Pensamento, realizado em Porto Alegre, em 2011) define o dualismo cartesiano mente/corpo como "teatro cartesiano" a partir da concepção de que a mente, em sua constituição fundamental, não tem nada de racional, pois é um pandemônio de processos neurais complexos e fragmentários, desprovidos de racionalidade intrínseca. A esse respeito, conferir seu já clássico livro Consciounssness Explained (New York: Back Bay Books, 1992). 
dominadas pelos conhecimentos adquiridos pelo cientista, a figura chave que inaugura $\mathrm{o}$ nascimento da ciência moderna, territorialidade exclusiva do masculino. Particularmente no seu ensaio "O nascimento do tempo masculino" (Temporis Masculus Partus, 1605), a metáfora da união sexual entre o cientista e a natureza que permeia todo o texto assume, não raro, a conotação de violência associada a um estupro, ou seja, o poder da natureza é tomado à força para que seus mistérios sejam devassados pelo cientista. Não resta dúvida de que tanto o racionalismo filosófico quanto o empiricismo científico, consagraram, a seu modo, os dualismos cultura/natureza, mente/corpo e sujeito/objeto como absolutos hierárquicos, pautados pelo ideal de uma mente que, supostamente, transcende toda a diferença sexual, mas que se inscreve, no conjunto dos discursos, claramente como masculina, pois é em relação a ela que o feminino emerge como lugar da diferença, codificada pela materialidade do corpo, não raro inserido no contexto da discussão em torno dos animais, os quais são, via de regra, reduzidos à condição de máquinas reprodutoras.

$\mathrm{Na}$ impossiblidade de aprofundar as discussões filosóficas e considerar seus desdobramentos até o século XIX, uma vez que este não é o objetivo do presente texto, não poderia deixar de destacar que os dualismos referidos acima são constituídos em cadeias de significações impregnadas por um simbolismo sexual que se mantém coerente ao longo dos tempos, apesar das variáveis históricas e das diferenças temporais que incidem sobre o desenvolvimento da tradição ocidental. Por exemplo, a metáfora do corpo como pura matéria, associada à natureza, e os dualismos mente/corpo, razão/emoção, cabeça/coração, lidos invariavelmente pelo paradigma homem/mulher, são constitutivos da concepção do feminino e matriz da noção popularizada até os dias de hoje, de que o sexo está na e é a mulher ${ }^{3}$. Cabe ressaltar que o feminino é, muitas vezes, um conceito descolado da mulher enquanto realidade empírica, outras vezes é sinônimo do ser mulher de forma que não existe uma identidade direta or relação de correspondência entre gênero simbólico e gênero estrutural, o que não impede de reconhecer o fato de que ambos são, efetivamente, duas instâncias que se imbricam e interagem na história de gênero e sua formação social. A exclusão metafórica do feminino da razão nos discursos hegemônicos do saber ocidental se alinha com a história literal da desvalorização e da exclusão milenar das mulheres dos campos da ciência e da cultura. Precisamente por essa razão, pode-se dizer que o desenvolvimento das ideias e seus protocolos filosóficos/científicos articulam uma grande metáfora cultural com autoridade de moldar a arquitetura de sua expressão social. $\mathrm{Na}$ operação simbólico/cognitiva dessa metáfora, os dualismos presentes na conceituação da diferença produzem uma assimetria de gênero, expressão de uma estrutura de poder político que se legitima através de um sistema de oposições tidas como naturais ou essenciais. Tal operação configura um processo de mascaramento através do qual o falocentrismo esconde suas ficções para fabricar uma verdade única, como bem coloca Judith Butler ao examinar a manipulação epistêmico-discursiva na construção do ser mulher como "fato natural" pelo sistema ontológico que produz o natural como se fosse o efeito de um real original e inevitável (BUTLER, 2003).

Como já foi discutido por pensadoras feministas, dentre as quais destaco a filósofa Susan Bordo em seu livro de 1987, The Flight to Objectivity [A fuga para a objetividade], o Iluminismo, que moldou a modernidade de forma inconteste tanto no

\footnotetext{
${ }^{3}$ Essa visão foi reforçada por Freud que, em seu Para além do princípio do prazer (1920) afirma ser a cultura o produto do trabalho dos homens porque somente esses são capazes de reprimir a sua natureza sexual.
} 
plano das ideias quanto no campo político e social, se baseia em uma epistemologia radicalmente masculinista, com consequências dramáticas para o estatuto das mulheres e para as formas pelas quais seus corpos foram e ainda são, em larga medida, construídos nos discursos patriarcais. Para Bordo, o corpo é um texto da cultura, na medida em os discursos sobre ele o transformam em uma poderosa forma simbólica que absorve os regulamentos, os valores, as hierarquias, as práticas sociais e mesmo os investimentos metafísicos de uma cultura. Segundo ela, a partir de uma visão histórica, a normalização do corpo feminino, que é a única forma de opressão que atravessa, mesmo que sob diferentes graus e formas, questões de idade, raça, classe e orientação sexual, precisa ser reconhecida como uma estratégia surpreendentemente duradoura e flexível de controle social. Desnecessário dizer que esse controle foi e é exercido por meio de uma ideologia do conhecimento, produzida no âmago de sua própria estrutura, ou seja, os dualismos: onde há dualismos, há uma oposição binária calcada no privilégio de um termo sobre o outro, e onde há hierarquia, há controle. Por exemplo, as representações culturais do corpo feminino na perspectiva da reprodução da femininidade pressuposta na relação com a natureza, constituiu a clássica equação que dominou a antropologia no século XX: o homem está para a cultura assim como a mulher está para a natureza. Em seu influente artigo, intitulado "Is Female to Male as Nature is to Culture?", Sherry Ortner (1974) apresenta evidências empíricas que contrariam os termos da equação e argumenta que mesmo que o dualismo natureza/cultura, implicado na equação e na relação dessa com a opressão das mulheres não seja um universal, mas historicamente determinado, ela tem sido uma dominante no pensamento ocidental. Com efeito, em muitos discursos acadêmicos e mesmo no âmbito da cultura em geral ${ }^{4}$, emerge uma versão homóloga, popularizada no nível de estereótipo: o homem está para a razão assim como a mulher está para a emoção. A referida versão ratifica a repressão teórica do feminino presente na filosofia, e a consequente exclusão da mulher da racionalidade ${ }^{5}$.

A ênfase na figura da mulher irracional na modernidade, segundo Susan Hekman em seu Gender and Knowledge (1990), é decorrente da significação do feminino que emerge com o advento da ciência moderna. Hekman argumenta que, no pensamento ocidental, a natureza sempre foi concebida como feminina, entretanto, o sentido do feminino incorporado à natureza se alterou radicalmente no período

\footnotetext{
${ }^{4}$ A título de ilustração, referimos a crônica de David Coimbra, formador de opinião do jornal Zero Hora, intitulada "Novas mães, novos pais", na qual ratifica a reprodução da feminidade ao criticar as mães de hoje e culpar suas conquistas pela depressão e decadência moral da sociedade, no melhor estilo de pregação religiosa: "a figura da mãe é poderosa demais para ser substituída por pais em meio período ou por babás em período integral. O resultado é a depressão endêmica e a decadência moral, ambas subprodutos da carência emocional. Por que alguns bandidos não se limitam a roubar, e usam de crueldade? Por que as pessoas são agressivas nas redes sociais, no trânsito ou no contato com indefesas operadoras de telemarketing? Por que as pessoas têm cada vez menos respeito pelas outras pessoas? Porque não tiveram mãe o suficiente. Porque não tiveram AMOR DE MÃE o suficiente". Disponível em: http://wp.clicrbs.com.br/davidcoimbra/2012/03/23/novas-maes-novospais/?topo=13\%2C1\%2C1\%2C\%2C\%2C13. Acesso em: 27 de março de 2012.

${ }^{5}$ Com relação a esse ponto, considero pertinente a reflexão de Toril Moi sobre o pensamento patriarcal em seu What is a Woman?: "The fact that philosophy presents woman as that which relentless undermines man's rational endeavors, is not an ideological coincidence. It is the very structure of scientific thought which here is revealed. [...] Philosophy itself creates its own inner enemy: femininity becomes the necessary support and signifier of rationality, operating within it as an eternal shadow that cannot be dialectically absorbed, neither obliterated nor fully assumed by the discipline" (MOI, 1999, p. 357).
} 
moderno. Em tempos pré-modernos, a natureza apresentava duas codificações: a mãe nutriz e o feminino selvagem e indomável. Portanto, a imagem feminina da natureza articulava noções que coexistiam como imagens orgânicas de uma estrutura unificada do cosmos e da sociedade e que eram vistas como associadas tanto ao poder benevolente da criação quanto aos seus poderes destrutivos, expressos nas fomes, tempestades e desastres naturais. Essas noções produziram uma atitude ambígua com relação à natureza: de um lado, o respeito, que impunha certos constrangimentos culturais em relação à sua exploração, de outro, o desejo de controlar o seu poder, mas que ainda assim reconhecia a força selvagem de seu mistério. Ainda segundo Heckman, a concepção mecânica da natureza que começou a se delinear na Renascença vai colocar a ênfase na natureza como desordem e caos, ênfase essa que, sem dúvida, baliza o pensamento científico até o advento da teoria de Darwin, no século XIX.

Se em tempos pré-modernos, um dos aspectos da ideologia social sobre a relação mulher/natureza veiculava a crença na capacidade ilimitada da mulher para o mal, encarnado na figura das bruxas da Idade Média, significativamente exterminadas durante a Inquisição, no período moderno essa crença ganhou estatuto de verdade. Em outras palavras, foram destacados os princípios da desordem e do mal para justificar a necessidade de controle da natureza e do feminino ${ }^{6}$. Embora com outro enfoque, a frase "desencanto do mundo", formulada por Max Weber (1922) para definir o impacto dos processos que configuram o mundo moderno, parece-me apropriada no contexto das questões aqui tratadas. Com efeito, uma compreensão crítica dos processos históricos e econômicos que inauguraram a modernidade ocidental não pode deixar de reconhecer certas confluências entre fenômenos distintos e, aparentemente, sem relação direta ou explícita. Pode-se considerar, nesse sentido, que o desenvolvimento da racionalidade científica com vistas ao conhecimento da natureza, a demanda por uma ética sexual pautada na necessidade de domesticar as mulheres e o processo capitalista na base da expansão europeia que levou à conquista de outras terras e gentes não são fenômenos excludentes e nem aleatórios, mas entrelaçados por uma mesma matriz moderna: o desejo de controlar o outro e de integrá-lo a um projeto de domínio ${ }^{7}$. É nessa chave histórica que se processou um forte investimento ideológico no sistema sexo-gênero ${ }^{8}$, fundamento para a domesticação do feminino pela força do constructo da mulher

\footnotetext{
${ }^{6}$ Em seu The Death of Nature: Women, Ecology and the Scientific Revolution (1983), Carolyn Marchant faz uma análise minuciosa da transição da visão de sociedade orgânica da Idade Média para a concepção moderna e mecaniscista, incluindo muitas referências a textos filosóficos, religiosos e literários do período que prenunciam a queda da velha ordem da natureza. De particular interesse é o capítulo intitulado "Nature as Disorder".

${ }^{7}$ A questão do domínio é o alvo da crítica de Theodor Adorno e Max Horkheimer em seu Dialética do Esclarecimento. Na leitura que ambos fazem do período moderno, salientam que foi nesse momento que os processos de racionalização do mundo chegaram ao ponto máximo de sua concretização de maneira que a modernidade é historicamente definida como a culminação do processo secular pela razão instrumental.

${ }^{8}$ Para Teresa de Lauretis, o gênero refere-se às representações, práticas, discursos e instituições socioculturais que constituem os indivíduos em homens e mulheres na medida em que os interpelam para introjetarem comportamentos e adotarem sentidos e valores que naturalizam a diferença sexual de modo que homens e mulheres possam exercer seus papéis no contrato social heterossexual. Em outras palavras, o gênero se fundamenta na essencialização da diferença, o sexo como dado biológico, e na oposição conceitual entre o masculino e o feminino, fundamento do sistema sexo-gênero que é uma construção sociocultural e um aparato semiótico produtor de assimetrias através de tecnologias de controle que garantem a sua reprodução (DE LAURETIS, 1987).
} 
feminina/corpo maternal, um modelo idealizado e consagrado por poderes seculares e religiosos e instrumental na codificação de práticas sociais. A lógica de um sistema que se pautou pela distinção radical entre reprodução e produção material de vida, pela separação das esferas do público e do privado, e pela divisão sexual do trabalho reconfigurou e estreitou a relação corpo feminino/ natureza para delimitar os sentidos do signo mulher e fixá-lo no materno. Dessa forma, a figura de um corpo feminino dócil, disciplinado e reprodutivo, em outras palavras, útil para uma cultura burguesa emergente no contexto da nova ordenação do mundo, fez com que o modo de produção capitalista viesse reforçar a lei patriarcal, tornando-a redundante. Julia Kristeva (1988), no clássico ensaio "Stabat Mater", faz uma observação muito pertinente ao afirmar que em muitas civilizações o feminino foi efetivamente incorporado ao materno, mas o fato do pensamento feminista na cultura ocidental ter identificado o materno como um dos principais locus de descontentamento pode ser explicado tendo em vista a construção específica do feminino sob a égide do capitalismo. Essa construção diz respeito a aporia forjada pelo sistema econômico e pelo modelo de pensamento que lhe dá suporte: de um lado, a consagração cultural da representação do feminino associado ao materno, de outro a desvalorização política e cognitiva da mulher cujo corpo, objetificado pelo olhar masculino e, em muitas situações, controlado por leis ditadas pelos homens, figura a própria alienação da mulher de si mesma. Essa é a razão pela qual Simone de Beauvioir, ao fazer a análise contundente dos efeitos do patriarcalismo no primeiro volume de $O$ segundo sexo (1949), afirma que um dos aspectos que distingue a mulher do homem é a escravização de seu corpo à espécie, o que leva de Beauvoir a uma percepção negativa do imago maternal. Sem adentrar na complexa articulação de seu posicionamento, podese compreendê-lo à luz do argumento que venho desenvolvendo, isto é, que na cultura patriarcal moderna, a concepção do feminino "natural" permanece circunscrita no dualismo corpo/mente, um binarismo em dominância que evidencia a vigência de uma metafísica prática no centro da modernidade ocidental. Digo prática porque o binário denota uma estrutura de poder político que atua através de um sistema de diferenças tidas como naturais. Se o ser mulher é definido irredutivelmente pela imanência de sua natureza, o sacrifício que a norma social lhe impõe é a abdicação do estatuto de humano. Isso significa dizer que o sentido culturalmente construido do corpo feminino como natural faz com que o natural não seja absolutamente um valor que possibilite o ser mulher ascender à categoria do humano. Como as questões levantadas nessa primeira parte de meu texto se traduzem em tramas romanescas e estratégias narrativas é o que desenvolvo a seguir.

\section{A REPRODUÇÃO DA FEMININIDADE}

A literatura, na condição de instituição humana e, portanto, histórica, constitui um lugar privilegiado para um trabalho de linguagem que produz sentidos e imagens indissociadas de valores articulados com codificações sociais. Nesse sentido, a literatura absorve, sedimenta e molda estruturas de referencialidade que remetem a modos de pensar e a padrões de comportamentos que, de uma maneira ou outra, responde às sobredeterminações histórico-sociais dos diferentes contextos geoculturais em que é produzida. E a narrativa, de modo particular, constitui uma forma tradicional e, portanto, quintessencial de conhecimento, porque ao veicular o conteúdo de uma 
história produz fronteiras ficcionais para a experiência através de convenções narrativas tais como trama, sequências, ênfases, pontos de vista, personagens, ações e resoluções cujos efeitos, em termos de representação e seu suporte retórico, disseminam comportamentos que são específicos e que dialogam, mesmo através de impasses ou tensões internas, com os elos da fábrica social de um determinado contexto. Desse modo, o lastro cultural da narrativa faz com que ela preencha uma função simbólica de caráter social, a de produzir conhecimentos que projetam e conferem legitimidade ao que pode ser dito, escrito e, em um certo sentido, realizado em uma cultura, segundo Jean-François Lyotard (1989). Considerando que nenhuma convenção é neutra, puramente mimética ou estética, e que valores artísticos são sempre valores sociais, pode-se abordar a narrativa romanesca como efeito de determinadas visões de mundo, scripts ideológicos que deixam claro as convergências de sentidos literário e social.

A perspectiva feminista, com seu vasto elenco de novos conhecimentos sobre a história, as ideologias da cultura e seus campos de saber, tem produzido reinterpretações da literatura sobre mulheres, seja escrita por homens ou por mulheres. E é nos processos crítico-interpretativos de releitura de romances representativos da literatura do passado que padrões de comportamentos e agencimentos narrativos tornam-se visíveis, fazendo com que nós, leitoras, tomemos consciência das presenças e ausências que estruturam os textos e definem os limites que pensávamos conhecer. Perguntas como o que é representado pelas personagens femininas, que resolução é dada aos conflitos processados no interior da narrativa e a partir de qual perspectiva de valores a representação é trabalhada e veiculada em suas nuances retóricas podem desvelar o trabalho do aparato ideológico do saber/poder narrativo, aparato definido por Rachel Blau DuPlesis (1983) como fábricas dos sentidos "naturais" e "fantásticos" através dos e com os quais vivemos 9 . No contexto desses questionamentos, a perspectiva de uma leitura política pautada, não na ficção de um conhecimento "real" e neutro da narrativa ficcional, mas em posicionamentos explícitos, se configura como resistência à certas concepções correntes da textualidade como função de uma indeterminação de sentidos flutuantes. O reconhecimento da existência de limites de sentido que são estratégicos, e portanto, de valor fundamental, não significa, todavia, destituir escritores de sua importância como sujeitos na história da literatura ou ignorar a questão da autoria, mas sim emancipar o autor e o/a leitor/a da camisa de força da autoridade interpretativa que, em última análise e, particularmente em se tratando de textos canônicos, se revela como uma forma de censura. A censura é inerente à reificação de interpretações que refutam ou excluem outras formas de interpretação a partir de premissas calcada no mito da objetividade e imparcialidade, tanto do ato de narrar uma história quanto no processo de sua análise. Nessa linha, pode-se definir a interpretação como resultado de certas escolhas cujo resultado é uma proposta de sentido do jogo de fazer-de-conta da ficção, uma proposta que não anula o agente narrativo, seus investimentos e posicionalidades na estrutura significativa da ficção, elementos importantes na construção das representações, do estabelecimento da autoridade narrativa e das fronteiras da textualidade. Nas palavras de Mieke Bal,

[...] interpretation is subjective and susceptible to cultural constraints. They define each reader as a cultural being: a participant in a continuous discussion about meaning. Endorsing that view entails an interest in framings - those

\footnotetext{
${ }^{9}$ No original em inglês, "[...] factories for the 'natural' and 'fantastic' meanings by which we live" (DUPLESIS, 1983, p. 3).
} 
constraints that make the process of interpretation of more general interest. This turns narrative analysis into an activity of cultural analysis. This is the case even if one's object of study is literary only (BAL, 2009, p. 12).

Em romances canônicos europeus do século XIX, particularmente aqueles que surgiram sob o influxo do realismo/naturalismo, as determinações sociais dos papéis femininos parecem ter ditado um ou dois enredos inexoráveis para as mulheres e neles, o tropo do corpo feminino, via de regra, definido radicalmente pela sexualidade, assume uma importância central não só pelo fato dos textos se alinharem às tendências estéticas dominantes de seu tempo no que diz respeito à caracterização de personagens femininas, mas também porque ambos projetam a imagem de uma sociedade cuja ordem e estabilidade está assentada em certas premissas sobre as relações entre corpo feminino, sexualidade e natureza. Dois romances merecem considerações tendo em vista as questões discutidas até aqui, pois são emblemáticos tanto pelo foco (uma certa obsessão, no século XIX, por mulheres adúlteras que perdem o status de "mulher natural") quanto pelo padrão da trama e sua resolução. São eles: Madame Bovary (1856), de Gustavo Flaubert e Ana Karenina (1875), de Leon Tolstoi. Ambos os enredos apresentam histórias de amor e casamento, transgressão e morte. A característica sacrificial das protagonistas, ambas casadas e mães, e que cometem suicídio ao final da narrativa, permite ler os romances como pedra de toque de uma cultura patriarcal e burguesa que reafirma seus valores mediante o expurgo do excesso feminino. O padrão narrativo, regido por uma economia linear da causa-efeito, aponta a inevitabilidade do suicídio das personagens muito antes da morte "real". A morte física é apenas a corroboração de uma morte psíquica anunciada através de uma série de indícios textuais.

Em Madame Bovary, a personagem Emma ilustra a trajetória de uma mulher ingênua e infeliz que rejeita, segundo o narrador, o martírio doméstico (capítulo VII, parte II) e se deixa levar por uma paixão adúltera, alimentada pelas fantasias que povoam uma imaginação exaltada pelo consumo voraz de romances em sua juventude. Manipulada pelas artimanhas de seus amantes, e sem saber como se libertar da sequência de acontecimentos que a levam a agir de forma insensata, Emma experiencia todas as fases do autoengano e da corrupção moral. Vivendo em permanente estado de colapso decorrente da lenta desintegração física e psicológica, busca a morte de forma dramática, ingerindo arsênico. Já moribunda, pede o espelho onde fita sua imagem por algum tempo. Nessa cena, narrador e leitor se tornam voyeurs de uma lenta agonia cuja enunciação desmascara o desejo existencial de Emma como forma de narcisismo, de maneira que o suicídio não é revolucionário ou heroico, mas esterilmente estético, transformado em espetáculo. Com isso não quero dizer que o narrador não tenha deixado explícito, em alguns momentos, sua crítica social às consequências dolorosas das convenções que limitam o mundo das mulheres, à sua subordinação legal e às condições que subtraem a sua expressão do desejo, seja o erótico, seja o de simplesmente ser. Ou seja, pode-se identificar um reconhecimento autoral do alto custo pessoal de desafiar a ordem social, o que abre a possibilidade de que Emma não se suicida por uma própria vontade e que sua morte não é senão o efeito do constructo ideológico do amor romântico e da febre de consumo burguês que literalmente a domina ${ }^{10}$. Contudo, se a crítica a esses valores pode somente tomar forma no sacrifício

\footnotetext{
${ }^{10}$ Importante lembrar que a publicação de livros constitui uma das primeiras formas de empreendimento capitalista e que esse novo mercado atinge seu ponto alto no século XIX, período áureo da prosperidade
} 
da figura de uma heroína, a crítica pretendida pode se tornar uma confirmação tácita da ordem vigente. Sob esse viés, pode-se dizer que a cena da extrema unção encolhe ou rasura a dimensão crítica do texto na medida em que ratifica a condenação moral da mulher transgressora no rito da purificação das partes do corpo da concupiscência e da luxúria.

Para todos os efeitos, Emma Bovary é reduzida a um corpo pecador, uma mulher que se atreveu a materializar seu desejo fora do casamento, o que fere as leis do gênero e a codificação da mulher como ser "natural". Se observarmos com atenção, desde o início da trama Emma é caracterizada pela sua ruptura com a boa natureza, a natureza mãe, matriz e nutriz. A maternidade não representa nenhum valor para ela e é flagrante o seu descaso pela filha antes mesmo do nascimento pois, em um de seus gestos impulsivos, gasta toda as economias para o enxoval do bebê com vestidos e rendas para si. É significativo o fato de que sua única relação com a natureza seja representada no amor pelo mar por causa das tempestades, e no gosto pelas ramagens verdes quando se esparramam por ruínas. Tempestade e ruínas são tropos característicos de romances góticos cujas tramas, na tradição escrita por mulheres no século XVIII e XIX, invariavelmente apresentam uma personagem feminina em perigo, a virtude ameaçada por algum tipo de violência mas, no contexto do romance de Flaubert, sinalizam a ruptura de Emma com a premissa da "mulher natural". O efeito moral de sua "queda" nas armadilhas de um desejo não domesticado pelo casamento, é acentuado, de forma contundente, pela voz do narrador, na descrição de seu vestuário. Há várias cenas e sequências nas quais Emma é descrita pela sua indumentária masculinizada, com trajes toscos de montaria e com um rebenque nas mãos, ou então, com cigarro na boca, vestindo calças compridas e colete, “à moda masculina", como assinala o narrador (FLAUBERT, 1971, p. 147). A masculinização da vestimenta altera radicalmente a recepção da imagem social de Emma, na medida em que sinaliza a perda do seu direito à femininidade, o que a identifica como uma mulher pública ou promíscua no contexto imagético cristão da tradição ocidental. Assim, levando-se em conta a forma com que é representada a personagem a partir da parte II, o destaque dado ao seu rebaixamento moral e degradação corporal, e a focalização do espetáculo da agonia e da morte de parte do narrador, perscrutador e impassível, torna-se evidente, para uma leitura crítica, que a fronteira entre estética e política não é nem firme nem exata, e que a famosa frase pronunciada por Flaubert, Madame Bovary c'est moi, não pode ser tomada a não ser como fina ironia.

O cenário da ação em Ana Karenina (1875) coloca em oposição os valores urbanos e os valores agrários e essa oposição é determinante na forma negativa com que a personagem Ana é representada e visualizada desde o início da trama: uma mulher urbana, dissociada da natureza, "desnaturada" segundo seu marido, um condição que pressupõe um julgamento e prescreve um destino. Os primeiro capítulos são repletos de percepções desfavoráveis à Ana, principalmente de parte da jovem Kitty, sua concunhada, cuja focalização lhe outorga um papel de destaque dentre o elenco dos outros personagens. Na clássica cena do baile (capítulos XXII e XXIII da primeira parte) e durante a dança da mazurka, Kitty observa com admiração, a graça e a beleza de Ana, mas também percebe que no encanto daquele corpo havia algo de terrível e cruel. Essa percepção é ratificada no momento em que pensa e diz para si mesma que há em Ana, uma sedução terrível e diabólica. Também na primeira parte, há elementos que

europeia letrada e cujo público consumidor de romances é constituído majoritariamente por mulheres. Nesse sentido, conferir o trabalho de Benedict Anderson, Imagined Communities (1983). 
prenunciam o destino trágico de Ana, muito antes de qualquer indício do envolvimento amoroso entre ela e o Conde Vronski. No capítulo XI há uma conversa sobre civilização e barbárie entre o Príncipe Oblonski e Levin, considerado um selvagem por suas ideias socialistas sobre o valor do trabalho e pela sua defesa da vida no campo. No decorrer da conversa, o assunto muda para a questão das mulheres decaídas ou prostitutas, em relação às quais Levin manifesta a sua repugnânica com veemência. E, para culminar, no capítulo XVIII, Ana houve o relato do homem que havia se jogado sob as rodas do trem na estação e cujo corpo destroçado é motivo de comentários entre as testemunhas, sendo que uma delas comenta que essa forma de morrer seria a mais fácil porque instantânea. Ana, visivelmente chocada pela cena é questionada por Oblonski e responde que o evento é um mau presságio. O fim trágico de Ana, que se joga nos trilhos de um trem que se aproxima, é pré-determinado na trama e o evento da morte é neutralizado pela representação do final feliz do casal Levin/Kitty. É sintomático que Kitty, que percebe o corpo de Ana como um corpo cruel, protagonize a mulher natural, idealizada pelo seu corpo casto, sem mácula, destinada a se tornar a fiel esposa de Levin e a incorporar os seus ideais telúricos. Não surpreende, portanto, que o casal projete os valores do casamento e da família, unidade básica de uma ordenação natural da sociedade emoldurada pela vida no campo, em oposição à percepção da "Babilônia decadente", definição da vida social em Moscou. Embora Ana seja uma das personagens femininas do século XIX que se destaca por ter sido delineada com grande compaixão, na parte final da trama ela é representada como uma mulher manipuladora e intempestiva, uma consciência percebida e representada como outro, destituida de positividade.

Pode-se dizer que a feminização do suicídio no século XIX em tramas construídas a partir de uma visão determinista que conduz à morte violenta das protagonistas, como é o caso em Madame Bovary e Ana Karenina, se alinha com a negação, realista porém perturbadora, da capacidade da mulher de fazer escolhas, o que reforça a percepção tradicional do caráter fraco das mulheres, suscetíveis de colapso mental, a chamada "nevrose" nos romances naturalistas. Em suas trajetórias, Ana e Emma se movimentam irremediavelmente para a margem da existência social até chegar a um ponto em que não há retorno. Em seu extremo isolamento, são reduzidas ao impulso irracional associado à sexualidade de um corpo indócil e não inteligível ${ }^{11}$ fora dos limites da doxa das socialidades patriarcais, razão suficiente para não sobreviverem na lógica da trama. Essa representação cultural do feminino irá culminar nos romances naturalistas os quais encenam o teatro do corpo histérico ${ }^{12}$, emanação de um útero possuído que pressiona o desejo sexual a ser dominado, ou através do tratamento da reclusão e do choque ou pelo casamento, visto como o mais eficaz remédio para salvar a mulher de si mesma. Mesmo que o suicídio possa ser tomado como um fato sociológico, a representação do corpo feminino se apoia na interpretação ontológica da sexualidade feminina indócil como fonte do mal. Nos termos de uma literatura sob o imperativo do realismo formal empenhado em não colocar em risco a ideologia que o

\footnotetext{
${ }^{11}$ Utilizo aqui a definição de corpo inteligível de Susan Bordo (1993), uma definição que incorpora representações científicas, filosóficas e estéticas do corpo, em sintonia com a conceitualização cultural do corpo feminino. Para ela, as representações dão suporte às regras normativas e práticas através das quais o corpo é treinado, moldado, se tornando obediente e socialmente adaptado de forma à responder às pressões e demandas sociais.

${ }^{12}$ A personalidade feminina histérica, a grande novidade médica do final do século XIX, ficou famosa nas aulas públicas de Jean-Martin Charcot, no Hospital La Salpêtrière em Paris. O termo "histérica" tornou-se quase permutável com o termo "feminino" na literatura do período (SHOWALTER, 1993).
} 
sustenta e segundo a qual o sujeito deve apresentar uma estrutura fundamentalmente inteligível e coerente, compreende-se que o suicídio constitui um fechamento lógico, uma resolução que responde à demanda realista do desfecho exemplar sob a aparência de livre arbítrio. Nesse sentido, a forma de ambos os romances e suas respectivas representações projetam, por deslocamento, um script ideológico em consonância com a norma cultural de um corpo feminino materno, fixo na ordem de uma natureza essencialmente benigna e domesticada, o que significa um corpo ao serviço da racionalidade funcional da ideologia burguesa patriarcal.

\section{DES-FIGURAÇÕES DO CORPO: CONVERGÊNCIAS INSUBMISSAS}

O corpo tem sido uma questão de grande destaque nas teorias feministas, desde a clássica afirmação de Simone de Beauvior sobre o quanto o corpo das mulheres inscreve sentidos culturais pressupostos em certas noções sobre a femininidade que, reforçadas socialmente, são introjetadas por elas a ponto de determinar a percepção de si próprias. Para Elizabeth Grosz (1994), cujos estudos agregam uma perspectiva feminista à sua releitura do trabalho de Merleau Ponty sobre a fenomenologia do corpo e, com isso, avança teoricamente com relação ao dualismo mente/corpo e às inscrições da relação corpo/natureza, todas as nossas concepções da realidade, conhecimento, verdade, política, ética e estética são efeitos de corpos sexualmente específicos e até agora, na nossa história, predominantemente corpos masculinos, o que significa que todas as referidas concepções estão implicadas em estruturas de poder descritas como modo de produção patriarcal, as quais governam as relações entre homens e mulheres. Segundo ela, repensar hoje as questões sobre o corpo representa um deslocamento epistemológico significativo, tanto para as Ciências Naturais quando para as Ciências Humanas.

A literatura, desde a antiguidade, constitui um repósitório imagético de construções culturais do corpo humano, mas é no romance do século XIX que as representações do corpo feminino assumem um caráter que se poderia qualificar como didático. A sobredeterminação da forma romanesca e a constituição da autoridade narrativa e seus códigos estético/sociais de representação tiveram um papel importante na socialização das leitoras no século $\mathrm{XIX}^{13}$ ao projetarem papéis e identidades socialmente aceitas e punir exemplarmente as transgressões. Se considerarmos o quadro da produção literária de autoria feminina a partir de fins do século XIX, pode-se dizer que a ficção inaugurou, de forma mais sistemática e insistente, novas e múltiplas formas de imaginar as relações entre mulher, corpo e natureza, não sem dramatizar certas ambivalências e impasses, mas rica em reconfigurações dessa relação na perspectiva de deslocamentos e resistências à construção do corpo como lugar da reprodução da femininidade, o que significa rasurar o princípio da mulher "natural" e questionar a metanarrativa patriarcal da subordição. Nesse processo, muitas escritoras do passado exploraram, com profundidade insuspeitada, a relação entre identidade, subjetividade, corpo e natureza, de tal maneira que seus romances podem ser tomados como precursores de teorias que viriam a se desenvolver posteriormente, nas últimas duas

13 Em seu Imagined Communities, Benedict Anderson estabelece a conexão entre capitalismo e tecnologias de imprensa escrita na criação de público leitor, incluindo, de modo particular, as mulheres, nos períodos de consolidação de consciência nacional. 
décadas do século XX.

$\mathrm{O}$ romance da escritora estadunidense Kate Chopin intitulado The Awakening $(1899)^{14}$ ainda é objeto de grande atenção de críticos que se dividem em polêmicas interpretativas suscitadas pelo seu desfecho - suicídio por afogamento - considerado, por muitos, como registro da rendição da personagem Edna Pontellier às pressões sociais e às convenções de seu mundo, o mundo da sociedade sulista crioula de New Orleans. O padrão narrativo é familiar: casamento e maternidade, paixão e morte, mas o desdobramento das sequências e eventos desvela uma economia narrativa e um agente narrativo em contraponto aos romances de Tolstoi e Flaubert. Refiro-me, inicialmente, às sequências dos primeiros capítulos que focalizam o desenvolvimento de Edna, uma alma apaixonada de artista que desperta para a sexualidade e para a descoberta de suas potencialidades durante as férias de verão no Golfo do México, a despeito da intransigência do marido e de suas pressões e cobranças com relação ao cumprimento de seu papel de mãe. A recorrência de referências ao mar, nos primeiro capítulos, descrito como uma "voz sem fim" em uma "canção de ninar que parece um lamento" (CHOPIN, 1972, p. 13) e que a alcança como "um amoroso e suplicante imperativo" (CHOPIN, 1972, p. 24) a convidar a alma "a errar por um tempo em abismos de solidão" (CHOPIN, 1972, p. 25) deixa evidente que não se trata apenas de um elemento do cenário, mas de uma presença capacitadora que toca uma corda receptiva de sua sensibilidade de forma a envolver suas percepções, suas emoções e seu corpo. O momento epifânico na noite em que Edna corajosamente nada sozinha mar adentro, quando todos já haviam desistido de tentar ajudá-la a superar seu medo do mar, é o momento inaugural de uma experiência física e sensual, perceptiva e existencial, que lhe abre as portas para uma nova dimensão de si. A cena apresenta todos os elementos de um encontro naturista: o mar em calmaria, uma lua brilhante, uma sensação de levitação, uma mistura de sentimentos de terror diante do desconhecido e de pura alegria ao descobrir sua força, tal como uma criança que cambaleia e cai e "percebe de repente seu poder e caminha pela primeira vez". A descrição continua:

[...] um sentimento de exultação tomou conta dela, como se alguma força revestida de significação lhe tivesse dado poder para controlar o funcionamento de seu corpo e de sua alma [...] Ela queria nadar muito longe, onde nenhuma mulher havia nadado antes. A medida em nadava, parecia procurar o ilimitado para nele se perder (CHOPIN, 1972, p. 47).

O impacto da concretude física da experiência lhe aguça os sentidos e seu corpo é tomada por uma intensa sensualidade. Em uma cena subsequente, Edna deixa o serviço religioso ao qual assistia e se refugia na cabana à beira-mar de Madame Antoine para se recuperar de uma tontura. Na cama simples de um quarto estranho, ela toca partes de seu corpo - as pernas, o cabelo, os dedos e seus braços, "observando muito de perto, como se fosse pela primeira vez, a qualidade e a textura fina e firme de sua carne" (CHOPIN, 1972, p. 62). Quando acorda, Edna pergunta a Robert, o objeto de seu enlevo romântico que chegara e a observava, quantos anos havia dormido.

Nesta cena, um dos momentos altos da iniciação de Edna ao conhecimento de si e que está associada à metáfora do despertar, o corpo assume a função metonímica do próprio existir pois nele converge um jogo de sensações visuais, táteis e sinestésicas e

\footnotetext{
${ }^{14}$ Como não há uma tradução em língua portuguesa do romance, todas as citações da edição em língua inglesa de 1972, pela Avon Books de New York, foram traduzidas por mim.
} 
registros psíquicos, o que significa dizer que a superfície do corpo recebe informação do exterior e do interior produzindo o que Elizabeth Grosz define como "dupla sensação", aquelas "em que o sujeito utiliza uma parte do corpo para tocar outra parte, um movimento que evidencia o intercâmbio de sensações ativas e passivas, de posições de sujeito e de objeto, do corpo e da mente" (GROSS, 1994, p. 35-36). Desse modo, a experiência subjetiva do corpo como forma sensível sublinha a indissociabilidade dos espaços corporais e psíquicos, desfazendo a oposição entre o interior e o exterior, o dentro e o fora. É precisamente essa interrelação que torna possível a inscrição do corpo e da subjetividade no eixo da diferença e do desejo, o qual se reveste de implicações políticas, uma vez que a diferença sexual não é apenas uma abstração, mas se materializa em um corpo, o corpo é de uma mulher e esse corpo é matéria da subjetividade, é o que lhe dá substância e existência. Lembre-se aqui a frase: "nadar onde nenhuma mulher havia nadado antes". O capítulo final do romance é um retorno à cena inicial da iniciação. O mar é um símbolo clássico associado ao renascimento feminino, um dos focos do clássico estudo de Annis Pratt em seu Archetypal Patterns in Women's Writings (1977). Ou então, em termos freudianos, o mar é associado à sexualidade e às estruturas do inconsciente. A resolução da trama na apoteose naturista que é a cena do suicídio não é compatível nem com a leitura de Pratt da função dos arquétipos, nem com a pulsão negativa associada ao desejo de regressão ao corpo materno, segundo a interpretação freudiana.

O Bildungsroman de Kate Chopin joga com as possibilidades semânticas do significante "despertar" de modo que para compreender o sentido do suicídio é preciso atentar para a sequência dos despertares de Edna em suas várias recusas ao longo da narrativa: 1) a recusa em aceitar as inevitáveis demandas associadas ao sentimento de amor pelos filhos que transformam, na percepção de Edna e nas palavras da narradora, mulheres como Adèle Ratignolle, em "mãe-mulher", "mulheres que idolatravam suas filhos, veneravam seus maridos e consideravam um privilégio sagrado se obliterarem como indivíduos e deixar crescer suas asas como anjos em um ofício religioso" (CHOPIN, 1972, p. 16); 2) a recusa ao romance e à paixão como índices de vulnerabilidade às expectativas sociais e à possessividade masculina, mesmo fora da convenção do casamento; e 3) a recusa da armadilha biológica que assegura as "mães para a raça" - palavras que ouve do doutor Mandelet ao assistir ao parto do sétimo filho de Adèle - e de correr o risco de gravidez indesejável como resultado da atividade sexual. Dessa forma, o suicídio fundamenta-se na recusa à conformidade, na recusa à auto-ilusão e na recusa à reprodução, em um momento em que a personagem atinge o grau máximo de consciência de sua femininidade no contexto das limitações de sua cultura e das circunstâncias de sua história pessoal. Portanto, há uma consistência de caráter e motivo a sustentar a representação de seu forte corpo nu à mercê do sol e da brisa, dando suas braçadas para elevá-lo ao nível das ondas, enquanto sua força física começa se esvair. A resolução, ao contrário dos dois romances vistos anteriormente, é permeada pela subjetividade cúmplice da narradora que projeta uma imagem de imanência e trancendência na celebração da sinergia de um corpo no momento final em que a consciência exerce o ato de liberdade radical que é a liberdade de dizer não. A narrativa finaliza com a descrição dos momentos finais da percepção evocativa de Edna, em um cenário em que a narradora chama a atenção para a imagem sinestésica do mundo natural: " havia o zumbido das abelhas e o aroma almiscarado dos cravos enchia o ar" (CHOPIN, 1972, p. 190).

Em To The Lighthouse, da escritora inglesa Virgínia Woolf, publicado em 1927, 
a natureza é uma força onipresente e as personagens femininas estão relacionadas de várias e diferentes maneiras a essa força, de modo particular a Senhora Ramsay, que é a protagonista da primeira parte do romance, intitulada "A janela". A janela é uma metáfora da visão, moldura de mediação do interior e exterior, de espaços simbólicos e literais e, também, perspectiva que ordena o modo como a Senhora Ramsay vê e é vista pelos outros. Para o marido, filhos e amigos que visitam a família durante o veraneio, a senhora Ramsay é a materialização do princípio feminino, figura da mãe-terra cujo corpo natural e fértil, significativamente sempre envolto no xale verde, define sua forma social de ser. Nesse sentido, a Senhora Ramsay representa a antítese da ordem masculina, figurada no marido filósofo, o Senhor Ramsay, o que permite uma leitura da primeira parte do romance como uma narrativa das relações normativas de gênero no contexto específico e historicamente determinado da sociedade vitoriana, mas também como uma narrativa alegórica das relações hierárquicas predicadas no binarismo natureza/cultura que não é exclusivo das culturas dominantes do Ocidente, mas nelas se intensificaram pelas razões que aludi no início desse texto. Assim, a relação dos Ramsays é inevitavelmente uma zona de batalha, de polarizações e escaramuças em implicam na exaustão física e emocional da esposa, vista pelo marido como natureza em sua "adorável inocência sem defesas" (WOOLF, 1982, p. 31), visão compatível com seus comentários sobre a irracionalidade das observações da esposa sobre o tempo, o que, na sua interpretação, é um índice da insensatez das mentes femininas (WOOLF, 1982, p. 36). A narradora ironicamente pergunta: "quem poderia culpá-lo se ele presta homenagem à beleza do mundo?" (WOOLF, 1982, p. 40), "uma vez que, se, comparada com ele, o que ela dava ao mundo era desprezível"? (WOOLF, 1982, p. 43).

Com seu contante papel de mediadora das tensões entre o pai e seus oito filhos e entre seus hóspedes, a Senhora Ramsay busca unir as pessoas, conciliar as diferenças, interferindo nas interações sociais com as melhores das intenções, não raro à revelia dos sentimentos das pessoas, o que, ironicamente, ela mesma acusa o Senhor Ramsay de praticar na antológica cena inicial sobre o passeio ao farol:

[...] perseguir a verdade com uma falta de consideração pelos sentimentos dos outros tão impessionante, tão brutal, era para ela um ultraje tão horrível à decência humana que, sem responder, entorpecida e cega, baixou a cabeça como para deixar a saraivada de pedras, a enxurrada de água imunda respingá-la, sem qualquer censura. Não havia nada a dizer (WOOLF, 1982, p. 36).

O silêncio da Senhora Ramsay pode aqui ser entendido no contexto das pressões, interpelações e constrangimentos inerentes à construção social de sua identidade, incluindo a própria percepção de desvalorização cognitiva e política de si mesma, o que é certamente o efeito de um contexto em que prevalecem relações de poder desiguais e que constantemente a colocam em posição de subordinação ou desvantagem. Contudo, presumir que a subjetividade da Senhora Ramsay esgota-se em seus papéis sociais, que seus atributos femininos são efeitos de um corpo biológico concebido como natural e predicado no materno para estabelecer um elo causal entre corpo feminino e mulher natural, é reduzir as complexidades dessa personagem e fixá-la em um dos termos do binarismo de gênero. Na longa cena inical do romance há uma série de sequências que ressignifica o que sabemos sobre a Senhora Ramsay. A sua reação à intervenção do homem da razão e da cultura e sua lógica estéril que exige a verdade em linguagem transparente quando do argumento sobre as possibilidades de levar ou não o filho caçula 
ao farol no dia seguinte, é lançar mão de um expediente que lhe é familiar, seja para não confrontar e irritar o marido diante dos filhos, seja para salvaguardar uma parte de si, pois tem consciência do desdém daquele para com as mulheres, de modo geral.

Como saída estratégica de uma situação insustentável, o silêncio é carregado de negatividade transformadora, pois significa penetrar no âmago pontiagudo da escuridão, uma metáfora do abandono da personalidade social e do acesso a um espaço iluminado que a permite experienciar uma unidade do ser em si e para si. Este espaço interior, onde a Senhora Ramsay acredita poder se movimentar como lhe convém sem ser observada, é repleto de atividades cognitivas e perceptivas que integram os sentidos de uma realidade subjetiva e corporal, com a realidade exterior de um mundo sensível e impessoal. Desse espaço, ela olha os objetos, sente e pensa sobre eles, ao contrário do Senhor Ramsay que, segundo ela, nunca olhava para as coisas a despeito de sua obsessão com as relações sujeito/objeto e a natureza da realidade: "a compreensão a deixava frequentemente atônita. Mas será que ele notava as flores? Não. Será que notava a paisagem? Não. Será que notava mesmo a beleza de sua própria filha..." (WOOLF, 1982, p. 72). Se, para a Senhora Ramsay, olhar as coisas é uma forma de conhecimento, como se pode, pensa ela, pretender alcançar a verdade sem olhar para elas? O capítulo XI, da parte I, se destaca em particular, pois constitui um núcleo importante da caracterização da Senhora Ramsay com relação à natureza:

Estranho que, quando a pessoa está sozinha, se apega às coisas, aos seres inanimados: árvores, córregos, flores. Sentia que essas coisas a expressavam; sentia que se transformavam nela mesma; sentia uma ternura irracional como (olhou o feixe de luz penetrante) se fosse por si mesma (WOOLF, 1982, p. 66).

Nessa cena a subjetividade mergulha em uma experiência sensorial do corpo em contiguidade com os elementos da natureza sensível e registra a convergência entre os processos de sentir e de pensar, gerando uma modalidade de ser cuja resposta afetiva irradia o ser e o seu entorno, representado no texto pelo olhar que se volta ao feixe de luz do farol. É o olhar, este movimento por dentro e para fora do corpo e associado à figura do olho como "janela do ser" - sugestivamente o título da parte I é "A janela" que confirma a presença de uma subjetividade corporificada. Esse corpo não é simplesmente uma entidade a-histórica nem pré-cultural, mas um corpo sexuado que demarca o espaço-tempo de sua historicidade singular e finita, situado em uma realidade vivida, marcada pela interação dos sentidos com as coisas. Como morada do ser, o corpo da Senhora Ramsay mostra-se como um outro modo de ser-no-mundo que não separa a resposta mental e a sensível, a mente e o corpo, o sujeito e o objeto. A representação de autonomia da subjetividade corporificada nessa cena sugere a impossibilidade de afirmar que os constrangimentos sociais que dão forma à sua identidade social de gênero determinam sua experiência, ou então, que há uma continuidade inunterrupta entre estrutura e vida subjetiva, entre o corpo constituído no simbólico heterossexual cujos discursos regulam sua materialização e as formas da experiência corporal. Seguindo esse raciocínio, poderia se afirmar que a subjetividade é sempre corporificada, mas o corpo feminino, tal como representado na narrativa de Woolf, não carrega somente a marca biológica do sexo nem se reduz a uma superfície passiva sobre a qual são impressas significações culturais. Isso significa reconhecer que o corpo e a subjetividade não estão totalmente subjugados aos efeitos da opressão e que a subordinação da Senhora Ramsay ao encenar seus papéis sociais não define quem ela 
é.

Um outro aspecto relevante na primeira parte de Passeio ao farol é a representação de uma relação singular e terna da Senhora Ramsay com certas imagens que são recorrentes no ângulo de sua visão: as ondas, o farol e a luz que dele emana. Como toda imagem é também uma linguagem, esses elementos deixam de ser apenas aquilo que está lá, no espaço exterior, para se constituir em elementos da subjetividade. Tomando o conceito de imagem corporal desenvolvido por Elizabeth Grosz ${ }^{15}$, poderiase dizer que tais elementos funcionam como imagens do corpo, na medida em que são efeitos de um investimento psíquico que converte imagens do exterior em sentidos que retornam e se integram ao corpo, através de sensações visuais, sinestésicas e espaciais. A espacialidade que circunda por fora e por dentro do corpo é crucial para definir os limites e as formas das imagens corporais, cujos sentidos sinalizam uma forma de autopercepção e autoconhecimento no contexto da experiência única da identidade. Por esse viés, se compreende a razão da intensa relação da Senhora Ramsay com as imagens citadas, uma vez que elas efetivamente indiciam a imagem de sua identidade em um corpo cujas fronteiras são constantes como as ondas do mar, firmes como o farol e protetoras como a sua luz-guia. Esses processos de projeção, identificação e internalização que conferem estrutura e significação aos momentos de "escuridão" da personagem, subvertem as determinações culturais do anjo do $\operatorname{lar}^{16}$ e alçam a personagem a um patamar de conhecimento e sabedoria sobre a verdade da existência ao qual seu marido filósofo jamais sonhou ascender. A consciência de que tudo é efêmero como o arco-íris culmina na visão epifânica de imanência e transcendência da Senhora Ramsay ao presidir o jantar que congrega a "sua comunidade de sentimentos" na despedida da família da Ilha de Skie. Sob a focalização cúmplice da narradora, a Senhora Ramsay pensa consigo mesmo que "são tais momentos [...] que fazem a vida valer a pena" $" 17$.

Os romances de Chopin e de Woolf constituem um projeto estéticoepistemológico que intervém nos imaginários culturais sobre os sujeitos mulheres e abrem possibilidades para além das estruturas dadas, desfazendo molduras de discursos e de fronteiras retóricas e com isso, deslocando paradigmas do saber patriarcal. As estratégias de des-figuração do corpo feminino na representação ficcional das experiências das personagens desessencializam os dualismos caros à cultura ocidental, particularmente a naturalização do corpo como matéria sem substância, uma pura exterioridade, assujeitada ao constructo simbólico da "mulher natural" predicado na capacidade gerativa. É certo que "corpo", em se tratando de literatura, é apenas um signo, mas na medida em que é representado, no sentido estético de re-apresentação e no sentido político de estabelecer um contraponto a uma imagem concebida com grande voltagem ideológica nos discursos da cultura, a sua narrativização como des-figuração ganha elevância por constituir um signo indicativo da resistência à interpretação mimética da relação mulher/natureza presente nos discursos patriarcais. Nos romances

\footnotetext{
${ }^{15}$ Essas noções são desenvolvidas, particularmente, no capítulo "Body Images: Neurophysiology and Corporeal Mappings" (GROSZ, 1994).

${ }^{16}$ Em seu ensaio "Profissões para as Mulheres" (1931), Woolf afirma que assassinar o anjo da casa, o ideal de feminidade repreentado em um poema de Coventry Patmore que se tornou muito popular na era vitoriana, deve constituir a ocupação de uma mulher que escreve. In: WOOLF, W. Collected Essays, Vol. II (1967).

${ }^{17}$ Essa é minha tradução de "of such moments, she thought, the thing is made that endures". A tradução da edição em português interfere no original: "é desses momentos que se compõem, pensou, tudo o que deve permanecer para sempre. Isto permanecerá” (WOOLF, 1982, p. 105).
} 
em questão, a corporealidade torna possível às personagens femininas viverem uma gama de sensações e percepções que dificilmente poderiam ser explicadas em termos do corpo como locus da reprodução da femininidade, na concepção de tecnologias de gênero de Teresa de Lauretis ${ }^{18}$, ou em termos exclusivos de performatividade de gênero, concepção desenvolvida por Judith Butler (2003).

A despeito do apagamento da imagem da "mulher natural", a presença da natureza permanece fonte inesgotável de metáforas que ressignificam o corpo como uma realidade situada e experienciada, cujas implicações perturbam a socialização das personagens nas normas de gênero. Este fato coloca em relevo, de um lado, a importância da escrita como forma de agenciamento em sua potencialidade de intervenção, de outro, a importância da poièsis, o poder criativo e desestabilizador de um fazer que configura uma modalidade de trabalho cultural ${ }^{19}$, tanto no sentido de articular representações literárias como um lugar produtivo de rasuras de discursos normativos, particularmente ao deslocar, no âmbito destes, a centralidade da consciência como instância última de geração de sentidos, quanto de abrir fissuras e gerar ruídos na dinâmica da reprodução das relações de poder e das desigualdades de gênero. Ao iluminar personagens cujas sensibilidades se libertam, de forma dramática ou oblíqua, das malhas de identidades moldadas pelo imperativo da reprodução da femininidade que as define como a outra do falocentrismo, os textos projetam matéria de experiências que fundam perspectivas excluídas pelos discursos e valores patriarcais, reinventando, nesse processo, novas histórias e novos saberes sobre as formas do humano das mulheres.

\section{BIBLIOGRAFIA}

ADORNO, Theodor e HORKHEIMER, Max. Dialética do esclarecimento. Rio de Janeiro: Jorge Zahar, 1985.

AGOSTINHO. Confissões. São Paulo: Nova Cultural, 1999.

ANDERSON, Benedict. Imagined Communities. London: Verso, 1983.

ARISTÓTELES. On The Generation of Animals. Trad. Arthur Platt. Disponível em http://ebooks.adelaide.edu.au/a/aristotle/generation/. Acesso em 30 de janeiro de 2012. ARISTÓTELES. Política. Trad. Torrieri Guimarães. São Paulo: Martin Claret, 2004. BACON, Francis. Novum organum: verdadeiras indicações acerca da interpretação da natureza. Nova Atlântida. São Paulo: Abril Cultural, 1979.

BACON, Francis. Temporis Masculus Partus. Disponível em: http://www.archive.org/stream/worksfrancisbaco07bacoiala\#page/n11/mode/2up.

Acesso em: 15 de janeiro de 2012.

${ }^{18}$ Para Teresa de Lauretis, o gênero se refere às representações, práticas, discursos e instituições socioculturais que constituem os indivíduos em homens e mulheres na medida em que os interpelam para introjetarem comportamentos e adotarem sentidos e valores que naturalizam a diferença sexual de modo que homens e mulheres possam exercer seus papéis no contrato social heterossexual. Em outras palavras, o gênero fundamenta-se na essencialização da diferença e na oposição conceitual entre o masculino e o feminino, pilar do sistema sexo-gênero, que é, por sua vez, uma construção sociocultural e um aparato semiótico produtor de assimetrias através de tecnologias que garantem a sua reprodução (DE LAURETIS, 1987).

${ }^{19}$ De acordo com Barbara Johnson (1998, p. 13). 
BAL, Mieke. Narratology. 3 ed. Toronto: The University of Toronto Press, 2009.

BAR ON, Bat-Ami (editor). Engendering Origins. Albany: The State University of New York, 1994.

BORDO, Susan. The Flight to Objectivity. Albany: State University of New York Press, 1987.

BORDO, Susan. Unbearable Weight: Feminism, Western Culture and The Body. Berkeley: The University of California Press, 2003.

BUTLER, Judith. Problemas de gênero. Rio de Janeiro: Civilização Brasileira, 2003.

CHOPIN, Kate. The Awakening. New York: Avon Books, 1972.

COIMBRA, David. "Novas mães, novos pais". Jornal Zero Hora on line: http://wp.clicrbs.com.br/davidcoimbra/2012/03/23/novas-maes-novos- pais Acesso em: 27 de março de 2012.

BEAUVOIR, Simone de. O segundo sexo. Rio de Janeiro: Nova Fronteira, 2009.

DENNET, Daniel. Consciounssness Explained. New York: Back Bay Books, 1992.

DESCARTES, René. Discurso do método. São Paulo: Martin Claret, 2011.

DUPLESIS, Rachel Blau. Writing Beyond the Ending. Bloomington: Indiana University Press, 1983.

FLAUBERT, Gustave. Madame Bovary. 2 ed. São Paulo: Abril Cultural, 1971.

FREUD, Sigmund. Para além do princípio do prazer. São Paulo: Imago, 2006.

GROSZ, Elizabeth. Volatile Bodies: Toward a Corporeal Feminism. Bloomington: Indiana University Press, 1994.

HEKMAN, Susan. Gender and Knowledge. Boston: Northeaster University Press, 1990. JOHNSON, Barbara. The Feminist Difference. Cambridge: Harvard University Press, 1998.

KRISTEVA, Julia. Histórias de amor. Trad. e introdução de Leda Tenório da Motta. Rio de Janeiro: Paz e Terra, 1988.

DE LAURETIS, Teresa. Technologies of Gender. Indiana: Indiana University Press, 1987.

MARCHANT, Carolyn. The Death of Nature: Women, Ecology and the Scientific Revolution. New York: Harper Collins Publishers, 1983.

LYOTARD, Jean-François. A Condição Pós-moderna. Rio de Janeiro: José Olympio, 2010.

MOI, Toril. What is a Woman? New York: Oxford University Press, 1999.

ORTNER, Sherry. Is Female to Male as Nature Is to Culture? In: ROSALDO, Michelle Zimbalist; LAMPHERE, Louise (editors). Woman, Culture and Society. Stanford: Stanford University Press, 1974.

PLATÃO. Timeus. Tradução para o inglês de Benjamin Jowett. Disponível em: http://www.gutenberg.org/files/1572/1572-h/1572-h.htm. Acesso em: 20 de fevereiro de 2012.

PRATT, Annis. Archetypal Patterns in Women's Writings. Bloomington: Indiana University Press, 1977.

SONTAG, Susan. Sobre coragem e resistência - discurso de abertura do prêmio Oscar Romero. In: __ . Ao mesmo tempo. Trad. David Rieff. São Paulo: Companhia das Letras, 2008. p. 190-201.

SHOWALTER, Elaine. Anarquia sexual: sexo e cultura no fin de siècle. Rio de Janeiro: Rocco, 1993.

TOLSTOI, Leon. Ana Karenina. São Paulo: Noval Cultural, 2003.

WEBER, Max. Science as a vocation. Disponível em: 
http://tems.umn.edu/pdf/WeberScienceVocation.pdf. Acesso em 15 de janeiro de 2012. WOOLF, Virginia. Collected essays. Vol. II. New York: Harcourt, Brace \& World, Inc., 1967.

WOOLF, Virginia. Passeio ao farol. Trad. Luiza Lobo. Rio de Janeiro: Nova Fronteira, 1982. 